\title{
Primary vitrectomy as a preventive surgical procedure in the treatment of severely injured eyes
}

\author{
J. FAULBORN, ${ }^{1}$ A. ATKINSON, ${ }^{2}$ AND D. OLIVIER ${ }^{1}$ \\ ${ }^{1}$ University Eye Clinic, Freiburg, West Germany; ${ }^{2}$ Moorfields Eye Hospital, London
}

SUMMARY The results of treating 72 severely injured eyes by primary vitrectomy combined with anterior and posterior segment reconstruction are presented. This approach aims at improving the visual prognosis by allowing fundus examination and immediate retinal surgery where indicated, and by preventing the more severe complications associated with vitreous and anterior segment disorganisation. The prospects for improved visual results and the problems encountered, particularly secondary haemorrhage, are discussed.

In some modern industrialised communities as many as $30 \%$ of all acute ocular cases attending hospital are due to injury (Minton, 1949), and ocular trauma accounts for $12 \%$ of all ophthalmic patients requiring hospital admission (Holland, 1964). Though perforating ocular injuries differ widely in type and severity, they carry a high risk of significant and permanent visual morbidity (Glees and Kleinhans, 1962; Avedikian and Simon, 1972; Heimann, 1972; Boudet et al., 1973; Watz and Reim, 1973). A knowledge and understanding of the principles involved in the management of ocular trauma can therefore make an important contribution to an ophthalmologist's therapeutic effectiveness.

Recovery of an eye from injury depends on 3 factors (Roper-Hall, 1969): (a) Degree of initial damage; (b) efficiency of early treatment; (c) satisfactory management of complications.

The ophthalmologist cannot influence the severity of injury in eyes that present acutely for treatment in the accident department, but his judgment as to whether an eye is irreparably damaged or not is clearly decisive at this initial stage. Immediate enucleation of severely traumatised eyes, without attempts at repair, was previously a widespread practice. It was based firstly on fear of sympathetic ophthalmitis and secondly on scepticism as to the likelihood of a worthwhile outcome. The difficulty in formulating an accurate prognosis on the basis of the initial examination findings, the preservation of vision in apparently devastated eyes (Heath, 1954), and the fall in the incidence of sympathetic ophthalmitis with modern surgical techniques and postoperative care (Brauninger and Polack, 1971) have

Address for reprints: Dr J. Faulborn, Universitäts-Augenklinik, Killianstrasse, D-78 Freiburg im Breisgau, West Germany all added support to the move away from such an approach (Paton and Goldberg, 1968). The idea that visual results and freedom from complications should be taken as criteria of successful treatment, rather than the percentage of enucleations, is now widely accepted.

Statistics showing the results of treating perforating injuries indicate that improvement has taken place both in terms of retention of cosmetically satisfactory eyes and, more important, visually useful ones. Examination of the series of cases presented by Moncreiff and Scheribel (1945) and by Snell (1945) shows that the number of eyes blinded or enucleated was nearly twice the number of those retaining a vision of $6 / 60$ or better. A reversal of this overall situation is shown by the results of the more recent series of Remky et al. (1967) and Watz and Reim (1973).

Developments underlying this change include the effective treatment of infection with antibiotics and the control of inflammation with steroids. Microsurgical techniques ensure more precise placement of sutures and accurate apposition of wound edges (Harms and Mackensen, 1967; Mackensen and Eberwein, 1972), challenging the surgeon to restore normal anatomy (Roper-Hall, 1969) or to reconstruct a functionally useful organ, utilising the remaining viable tissues.

In managing the more severe perforating injuries involving lens and vitreous, the conservative surgical techniques of abscission of prolapsed tissue and wound suture are insufficient to prevent complications which ultimately lead to severe visual impairment (Johnston, 1971; Boudet et al., 1973). These include chronic non-infective uveitis, phakoanaphylactic uveitis, reactionary haemorrhage, fibrous 
overgrowth, glaucoma, hypotony, vitritis, vitreous strand formation, and retinal detachment (DukeElder and MacFaul, 1972).

The concept that a mixture of damaged lens material and vitreous was a potent influence, promoting chronic intraocular inflammation, cyclitic membrane formation, vitreous strand formation, retinal detachment, hypotony, and phthisis led Kasner (1968) to formulate a more forthright approach to surgical management. In aiming to avoid the development of such complications, the surgical emphasis was being shifted from the primarily preservative in the direction of the preventive. Where appropriate this involved enlargement of the corneal wound, complete removal of all damaged lens material, combined with anterior vitrectomy. Such measures effectively removed damaged and potentially harmful anterior segment tissues and also, by removing the vitreous, eliminated the substrate in which strand formation might otherwise have subsequently taken place. This view of the pathogenesis of post-traumatic intraocular complications has received clinical and pathological support (Coles and Haik, 1972).

Based on these considerations, the treatment of severe injuries at Freiburg University Eye Clinic has undergone modification with the aim of achieving a primary reconstruction of the globe at the initial surgical procedure (Faulborn and Birnbaum, 1974). Particular emphasis is laid on the following points: (a) Adequate exposure of the injured structures to enable thorough assessment of the extent of the damage; $(b)$ removal of all traumatised tissue liable to act as a stimulus, source, or medium for intraocular inflammatory activity, fibroblastic activity, or neovascularisation; (c) reconstruction carried out using only structurally viable tissues; (d) visualisation of the posterior pole, so that reparative procedures to retinal tears, dialyses, etc., can be carried out.

The purpose of this study is, firstly, to present the results obtained after managing 72 severely injured eyes in this manner; secondly, to try to evaluate what benefits such methods bring in terms of the visual results obtained and the complications encountered in comparison to more conservative techniques; and, thirdly, to endeavour to define more clearly the problems encountered in treating such eyes, thus highlighting areas for further investigation.

\section{Materials and methods}

The material for this study comprised 71 patients (72 eyes) with severe perforating ocular injuries treated at the Freiburg University Eye Clinic between 1970 and 1975. In selecting cases for inclusion, a severe injury was defined as a perforation of the corneo-scleral envelope, resulting in prolapse or loss of intraocular contents and involving in addition damage to 2 or more intraocular structures. In practice the intraocular structures invariably damaged were lens and vitreous, together with other tissues in the majority of cases.

All cases were selected on the basis of the extent of the damage sustained by the affected eye, and this made for a somewhat more homogeneous group than is included under the heading 'perforating injuries' in many other published series.

Surgery was performed under general anaesthesia using a Zeiss Mk. 6 microscope, and descriptions of the procedure are published in detail elsewhere (Mackensen and Faulborn, 1974; Faulborn and Birnbaum, 1974). The great majority of cases included here were operated on and managed by the same surgeon (J.F.), this course ensuring a standardised technique and approach. Vitrectomy was by the open-sky method, in the early cases using Kasner's cellulose sponge technique, and later with a vitreous suction cutter apparatus designed at the Freiburg clinic (Hennig et al., 1972). In order to acquire accurate information follow-up examination was carried out on 45 patients; 15 patients were not recalled because the eye either had been enucleated or was blind from already documented causes. 11 patients could not be contacted.

The examination consisted of measurement of corrected visual acuity, assessment of the visual field, slit-lamp examination, tonometry, examination of the vitreous cavity and retina with the Goldmann triple mirror, fundus examination by indirect ophthalmoscopy with indentation, fluorescein angiography, and ERG.

\section{Results}

The follow-up period of treated patients extended over a maximum of 6 years 2 months. No patient with a follow-up of less than 6 months was included, and the average follow-up time was 3 years 6 months.

\section{AGE AND SEX DISTRIBUTION}

Of the 71 patients $54(76 \%)$ were male and $17(24 \%)$ female. The age distribution histogram (Fig. 1) shows that severe injuries affect predominantly younger people, $24 \%$ of cases occurring in those aged 11 to 20 and $73 \%$ in those under 40 years of age. This preponderance in children (Kobor, 1965) and young adults (Glees and Kleinhans, 1962; Holland, 1964) is already well recognised and documented. 
SEVERE PERFORATING INJURIES

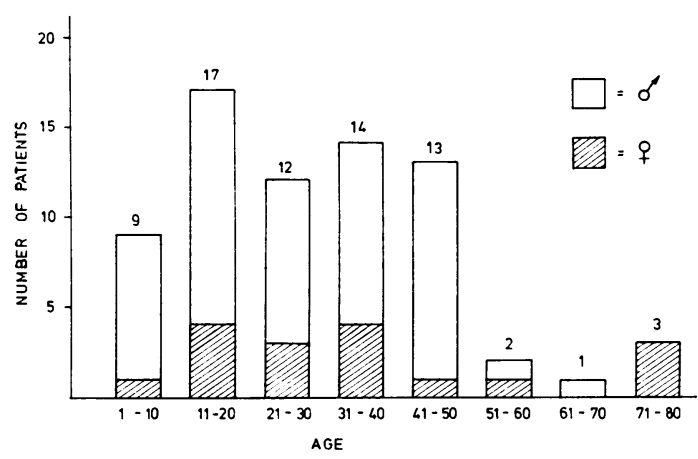

Fig. 1 Distribution of patients according to age and sex

\section{CAUSE AND TYPE OF INJURY}

Table 1 shows a statistical breakdown of cases in this series according to the activities and location of the patients at the time they sustained injury. Occupational activities predisposed to $44 \%$ of injuries. Road traffic accidents (RTA) formed the next largest group, and in comparison with other series (Roper-Hall, 1959) form a much larger proportion of cases. Compulsory wearing of seat

Table 1 Activity or location at time of injury

\begin{tabular}{lrr}
\hline & & $(\%)$ \\
\hline Industrial occupation & 26 & $(36)$ \\
Road traffic accident & 18 & $(25)$ \\
Sport, play & 12 & $(17)$ \\
House, garden & 10 & $(14)$ \\
Farming, forestry & 6 & $(8)$ \\
& - & $(100)$ \\
\hline
\end{tabular}

Table 2 Types of perforating injury

\begin{tabular}{lrc}
\hline & & $(\%)$ \\
\hline I: Blunt injury producing rupture & 8 & $(11)$ \\
II: Sharp injury & 43 & $(59)$ \\
III: Perforation with IOFB & 21 & $(30)$ \\
& $\overline{72}$ & $(100)$ \\
\hline
\end{tabular}

belts and the imposition of lower speed limits can be expected to reverse this trend (Müller-Jensen and Allmaras, 1968; Johnston, 1971).

Perforating injuries can be grouped into three categories according to the type of implement or material directly responsible (Table 2). Each type of injuring agent tends to have fairly specific mechanical effects on the eye, producing patterns of structural damage and posing surgical problems requiring particular techniques and equipment for their solution. Knowledge of the circumstances surrounding production of the injury has clinical relevance in planning the surgical approach to primary reconstruction of an injured eye. Consideration of the activity or location where the different types of injury occur shows that $83 \%$ of severe perforating injuries resulting from road traffic accidents were sharp penetrating ones, usually windscreen glass, and that $50 \%$ of severe perforating industrial injuries were from intraocular foreign bodies (IOFB), mostly magnetic. Fig. 2 shows the frequency of particular injuries in the different locations and indicates where eyes are especially at risk. Thus, $61 \%$ of all IOFBs occur in industry, $39 \%$ of all blunt injuries in the house or garden, and the largest proportion of sharp perforations $(34 \%)$ as a result of RTAs. Such figures assist in planning an intensification in the effectiveness of preventive measures, such as seat belts, protective goggles,

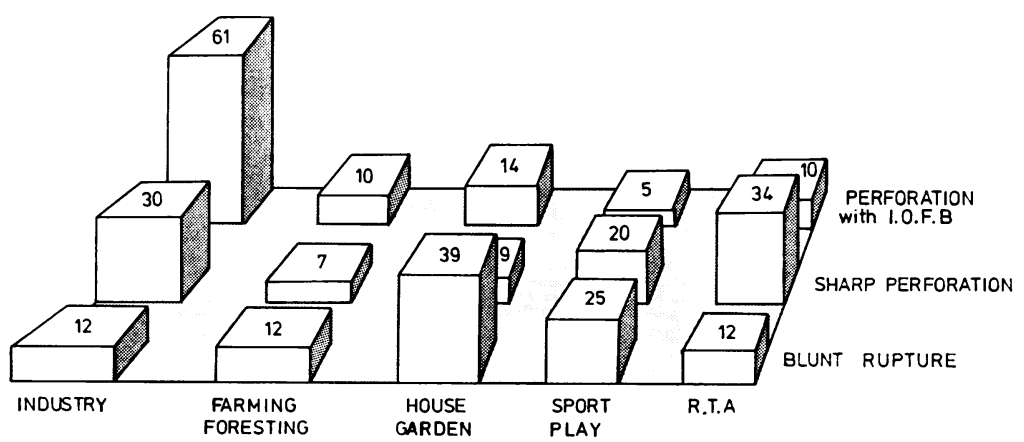

The figures on the columns give the frequency $(\%)$ with which

the given type of injury occurs in the different locations

e.g. $61 \%$ of all I.O.F.B. perforations are industrial.
Fig. 2 Relationship between type of injury and the location in which it is sustained 


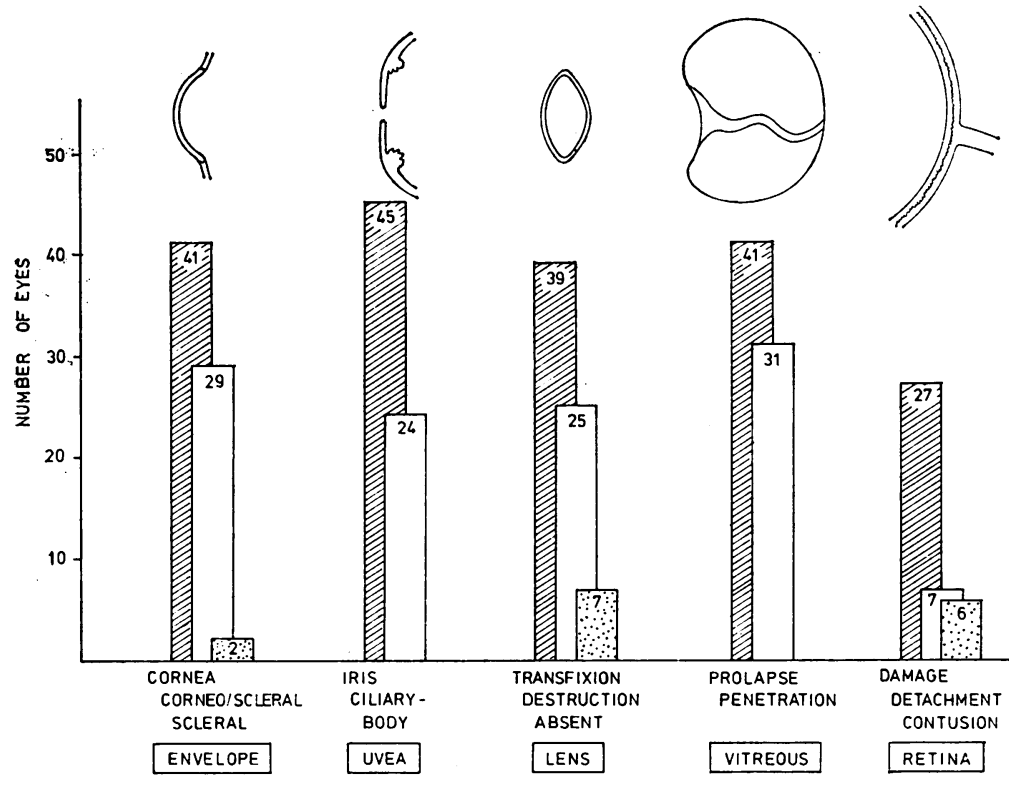

Fig. 3 Documentation of injured ocular structures etc., and underline the arguments in support of concentrating the sophisticated equipment for detection and extraction of IOFBs in centres serving highly industrialised areas.

\section{STRUCTURES AND TISSUES INJURED}

Painstaking assessment of the structural damage sustained by each injured eye is an essential first stage in primary reconstruction, great care being taken not to cause further insult to the tissues, a procedure possible only by using the microscope. Fig. 3 shows that the lens and vitreous were damaged in all the cases included in this series. Involvement of the anterior uvea occurred in 48 cases, comprising prolapse or damage to the iris in 45 cases and ciliary body trauma in 24 . With regard to the lens, in 39 cases there was a through-and-through injury, in 25 cases severe destruction, and in 7 cases a traumatic aphakia. Vitreous damage comprised prolapse in 41 eyes, and penetration of the vitreous substance in 31. Retinal injury of one form or another was evident in 40 cases; 27 showed direct retinal damage; 7 cases had a detachment present at the initial procedure, and contusional oedema or intraretinal haemorrhage was seen in a further 6 . Altogether there was injury to 2 intraocular structures in $12(17 \%)$ cases, 3 structures in $32(44 \%)$, and 4 structures in $28(39 \%)$ cases.

\section{INDICATIONS FOR VITRECTOMY}

On the basis of preoperative and operative assessment the perforating injuries included in this series underwent anterior segment debridement and vitrectomy. The decision to select out each case for vitrectomy was made on the basis of one or more of the following indications: (i) Injury of the lens with penetration or rupture of the posterior capsule and resulting vitreous/lens admixture; (ii) multistructure anterior segment injury with adherence of vitreous to damaged iris, ciliary body, lens, or cornea; (iii) perforating injury with vitreous haemorrhage and overt or suspected retinal damage; (iv) removal of a non-magnetic IOFB; (v) perforating injury with endophthalmitis. The frequency with which each situation was considered to be the main or subsidiary indication is shown in Table 3.

VISUAL RESULTS

The overall visual results based on the corrected visual acuity are shown in Table 4 . The patients were divided into 4 groups in accordance with the WHO classification for designating visual impairment (Roy, 1974) to facilitate comparability with other statistics.

Table 3 Indications for vitrectomy in 72 severely injured eyes

\begin{tabular}{llc}
\hline & $\begin{array}{l}\text { Main } \\
\text { indication }\end{array}$ & $\begin{array}{l}\text { Subsidiary } \\
\text { indication }\end{array}$ \\
\hline (i) Lens perforation & 31 & 11 \\
(ii) Anterior segment disruption & 37 & 3 \\
(iii) Vitreous haemorrhage & - & 26 \\
(iv) Non-magnetic IOFB removal & - & 2 \\
(v) Endophthalmitis & 4 & - \\
\hline
\end{tabular}




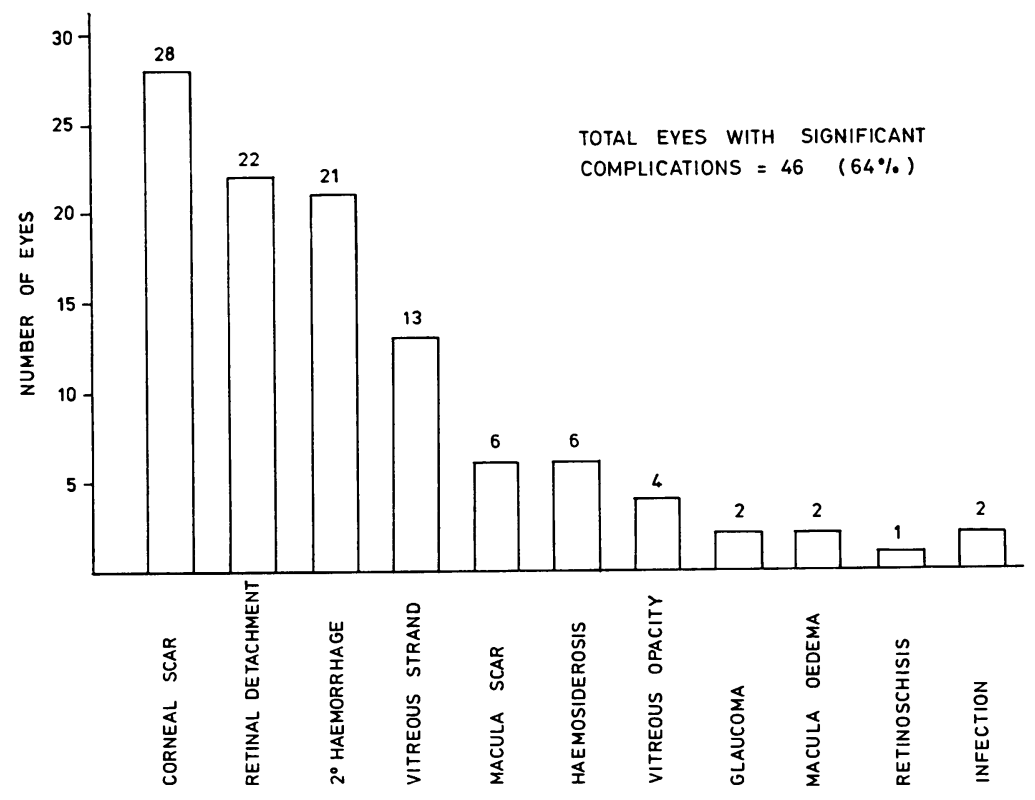

Fig. 4 Incidence of complications

Table 4 Visual results in injured eyes after primary reconstruction

\begin{tabular}{lcclll}
\hline Blind & $<\frac{6}{60}$ & $\frac{6}{60} \rightarrow \frac{6}{18}$ & $\frac{6}{12}$ or better & \\
\hline 19 & 14 & 18 & 21 & $=72$ \\
$(26 \%)$ & $(19 \%)$ & $(25 \%)$ & $(30 \%)$ & $=100 \%$ \\
\hline
\end{tabular}

\section{COMPLICATIONS}

In compiling the incidence of complications shown in Fig. 4 only those have been included which developed or became evident during the postoperative period. Lesions present at the initial examination are regarded by several authors as immediate complications (Johnston, 1971) but for the purposes of this paper are considered as preoperative or operative examination findings. The list of complications includes several categories of lesion. Injuries difficult or impossible to detect at the initial examination, such as macula damage, although clearly a direct consequence of the initial trauma, are legitimately included as complications only because of late discovery. Of greater concern in this study are complications such as vitreous strands, secondary haemorrhage, and retinal detachment, which develop as a result of the processes of regeneration and repair, and which begin within a few hours of the initial damage occurring (Coles and Haik, 1972). The objective of surgical treatment of injuries must be to reconstitute the structure of the injured eye, such that these processes progress purposefully and do not lead to the creation of further damage threatening ultimate visual recovery. The degree of success achieved in preventing or managing such complications is reflected in Figs. 5 and 6.

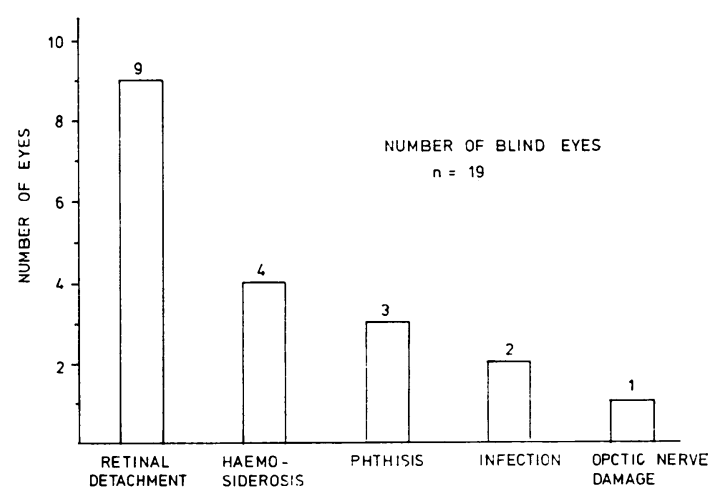

Fig. 5 Causes of blindness

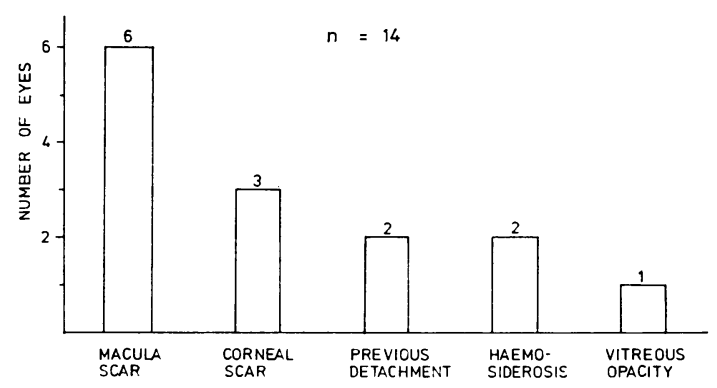

Fig. 6 Causes of $V A<6 / 60$ 


\section{RETINAL DETACHMENT}

The largest single cause of blindness in eyes in this series was retinal detachment. Overall, this condition occurred in 27 eyes $(37 \%)$, in 7 cases being recognised and treated at the time of primary surgery and in 22 cases developing subsequently. Successful reposition with one or more procedures was achieved in 18 eyes $(66 \%)$. A retinal hole was found in $45 \%$ of cases. In the 22 secondary detachments traction due to vitreous strand (11) or post-haemorrhagic strand formation was a factor in 18 cases and massive periretinal proliferation in 3 cases.

\section{SECONDARY HAEMORRHAGE}

This complication occurred in 21 cases $(29 \%)$, heralding a serious setback for the affected eye. The majority of episodes took place within a fortnight of injury, but in 2 cases 6 weeks elapsed. Analysis of the causes of blindness with reference to the effect of secondary haemorrhage is revealing. Thus, retinal detachment occurred in $57 \%$ of cases with haemorrhage and only $19 \%$ of cases without. The 4 cases of haemosiderosis were a direct result of haemorrhage, and it played a major role in the development of 3 phthisical eyes.

Exact data on the source of this haemorrhage were hard to obtain. Approached from the point of view of the tissues likely to bleed, the ciliary body might, on theoretical grounds, come under greatest suspicion. Ciliary body damage was indeed present in $50 \%$ of cases with secondary haemorrhage and only $21 \%$ of those without, but on this basis sclera could equally well be implicated. Injury to the iris appeared to be an occasional source, but retinal damage was statistically not significant.

\section{Discussion}

The results presented above have been obtained after treating a series of severe ocular injuries by methods which differ in important respects from more established conservative ones. In initiating this change to a more radical approach, the decision was made not to select out cases for inclusion in a control group, because the individual nature of each injury would make it impossible to determine at what point in the cases managed conservatively one should refrain from further surgical intervention. While the prime objective of this work was to assess the value of vitrectomy in severe injury therapy, it is clear that improved microsurgical instruments and techniques have also contributed to the results obtained.

More recently published series of the results of treating perforating injuries (Roper-Hall, 1959; Remky, 1965; Johnston, 1971) include many cases of a comparatively minor nature, making comparison difficult. Lens damage occurred in only $41 \%$ of the Munich severe cases and $31 \%$ of the Birmingham group. Nevertheless, the fact that the visual results in Table 3 break down into a pattern broadly similar to that in other series indicates that severe injuries do better visually after radical reparative procedures, a contention supported by Heimann (1972) and confirmed by a closer study of earlier statistics. In Johnston's series of 295 cases, of the 54 eyes with traumatic cataract and vitreous loss only $5(9 \%)$ recovered a visual acuity of $6 / 12$ or better, compared with $30 \%$ in this study.

Figs. 5 and 6 show that of the eyes blind or with vision less than $6 / 60$ only a small proportion resulted from primary tissue damage, the majority becoming irreparably damaged as a consequence of complications. Comparison with complications encountered in other series shows striking differences in incidence and severity. Cataract as a major cause of visual impairment is eliminated (cf. Johnston, 1971). Glaucoma occurred in less than $1 \%$ of cases compared with $10 \%$ (Johnston, 1971; Watz and Reim, 1973). Chronic non-infective uveitis was not encountered. Retinal detachment, however, occurred in $30 \%$ of cases, as one would expect with such injuries. The results of detachment surgery are comparable to the figures of Klöti (1972).

The high incidence of detachment developing as a secondary complication is disturbing. The role of vitreous destruction in the pathogenesis of detachment after perforating injuries was stressed by Witmer (1972). In this series it was intended to reduce the likelihood of traction detachment by avoiding incarceration of vitreous and preventing adherence to damaged structures with a fibroblastic potential. Any benefit radical debridement and vitrectomy may have conferred would appear to be much reduced by the effect of secondary haemorrhage, whose significance in detachment is well documented (Percival, 1972).

The possibility must be considered that early radical surgery predisposes to secondary intraocular haemorrhage, and it may be that major reconstructive procedures should be delayed for a period of time until the ocular condition stabilises (Machemer, 1976; Benson and Machemer, 1976; Hutton et al., 1976).

When the cases of haemosiderosis and phthisis are taken into consideration, $70 \%$ of the blind or enucleated eyes (Fig. 5) resulted from, or were associated with, severe secondary haemorrhage, which has emerged as the major problem being encountered.

Future efforts to improve the prognosis in severely injured eyes (managed along these lines) 
will therefore need to be directed at dealing more effectively with haemorrhage, either by removal, by promoting more rapid absorption, by chemical alteration to a harmless form, or preferably by finding and eliminating the source.

The quantities of blood which can be released into the vitreous cavity before causing significant retinal toxicity have been studied in monkeys (Sanders et al., 1975). Vitreous cavity lavage as a method, albeit relatively crude, of reducing amounts of intraocular haemorrhage to levels which can be tolerated and effectively dealt with by the eye's own reparative mechanisms is at present under study at the Freiburg clinic.

We thank Professor Dr G. Mackensen for his guidance in the management of cases included in this study and for his help and encouragement in the preparation of this paper. We are grateful to Frau Kukula for the diagrams.

\section{References}

Avedikian, H., and Simon, A. (1972). Klinische Monatsblätter für Augenheilkunde, 160, 198.

Benson, W., and Machemer, R. (1976). American Journal of Ophthalmology, 81, 728.

Boudet, C., Arnaud, B., and Rasoanaivo, R. (1973). Klinische Monatsblätter für Augenheilkunde, 163, 612.

Brauninger, G. E., and Polack, F. M. (1971). American Journal of Ophthalmology, 72, 967.

Coles, W. H., and Haik, G. M. (1972). Archives of Ophthalmology, 87, 621.

Duke-Elder, S., and MacFaul, P. A. (1972). System of Ophthalmology, vol. 14, pt 2, p. 383. London, Kimpton.

Faulborn, J., and Birnbaum, F. (1974). Klinische Monatsblätter für Augenheilkunde, 165, 409.

Glees, M., and Kleinhans, K1.-G. (1962). Klinische Monatsblätter für Augenheilkunde, 141, 287.

Harms, H., and Mackensen, G. (1966). Augenoperationen unter dem Mikroskop. Stuttgart, Thieme.
Heath, C. (1954). British Journal of Ophthalmology, 38, 567.

Heimann, K. (1972). Klinische Monatsblätter für Augenheilkunde, 161, 490.

Hennig, J., Faulborn, J., and Bernhard, F. (1972). Klinische Monatsblätter für Augenheilkunde, 161, 107.

Holland, G. (1964). Klinische Monatsblätter für Augenheilkunde, 145, 915.

Hutton, W., Snyder, W., and Vaiser, A. (1976). American Journal of Ophthalmology, 81, 733.

Johnston, S. (1971). Transactions of the Ophthalmological Society of the United Kingdom, 91, 895.

Kasner, D. (1968). Highlights of Ophthalmology, 11, 306.

Klöti, R. (1972). Modern Problems in Ophthalmology, 10, 395.

Kobor, J. (1965). Klinische Monatsblätter für Augenheilkunde, 146, 740.

Machemer, R. (1976). Personal communication.

Mackensen, G., and Eberwein, P. (1972). Klinische Monatsblätter für Augenheilkunde, 161, 257.

Mackensen, G., and Faulborn, J. (1974). Ophthalmic Surgery, $5,43$.

Minton, J. (1949). Occupational Eye Diseases and Injuries, p. 8. London, Heinemann.

Moncreiff, W. F., and Scheribel, K. J. (1945). American Journal of Ophthalmology, 28, 1212.

Müller-Jensen, K., and Allmaras, W. (1968). Klinische Monatsblätter für Augenheilkunde, 153, 803.

Paton, D., and Goldberg, M. (1968). Injuries of the Eye, the Lids, and the Orbit, p. 114. Philadelphia, Saunders.

Percival, S. P. B. (1972). British Journal of Ophthalmology. $56,462$.

Remky, H., Kobor, J., and Pfeiffer, H. (1967). Anales Instituto Barraquer, 7, 487.

Roper-Hall, M. J. (1959). Transactions of the Ophthalmological Society of the United Kingdom, 79, 57.

Roper-Hall, M. J. (1969). Ophthalmologica (Basel), 158, 12.

Roy, F. H. (1974). Annals of Ophthalmology, 6, 1049.

Sanders, D., et al. (1975). Albrecht v. Graefes Archiv für experimentelle Ophthalmologie, 197, 255.

Snell, A. C. (1945). American Journal of Ophthalmology, 28, 263.

Watz, H., and Reim, M. (1973). Klinische Monatsblätter für Augenheilkunde, 162, 648.

Witmer, R. (1972). Modern Problems in Ophthalmology, 10, 316. 